\title{
FORMAÇÃO E PERSPECTIVIDADE CONTROVERTIBILIDADE E PROIBIÇÃO DE DOUTRINAÇÃO COMO COMPONENTES BÁSICOS DA FORMAÇÃO E DA CIÊNCIA ${ }^{1}$
}

\author{
Wolfgang Sander \\ Tradução de Bento Itamar Borges*
}

\section{RESUMO}

$\mathrm{Na}$ discussão acadêmica alemã sobre a formação política, os princípios da controvertibilidade ${ }^{2}$ e da proibição da doutrinação valem, desde o Consenso de Beutelsbach, no final da década de 1970, como critérios de qualidade fundamentais e consensuais para a práxis pedagógica. Esta contribuição investiga se e em que sentido esses princípios poderiam, indo além da formação política, reivindicar validade para todo o âmbito da educação, e, de modo especial, para as escolas. Isso será feito em três passos: primeiramente, a partir do Consenso de Beutelsbach, a multiperspectividade ${ }^{3}$ será fundamentada como princípio para todas as

\footnotetext{
* Doutor em Filosofia pela Universidade Federal de Minas Gerais e Pós-doutor em Filosofia pela PUCRS. Professor do Instituto de Filosofia e do Programa de PósGraduação em Filosofia (Mestrado) da Universidade Federal de Uberlândia (UFU). E-mail: bentoib@gmail.com

1 Tradução autorizada em 07/10/2010 do original: Bildung und Perspektivität - Kontroversität und Indoktrinationsverbot als Grundsätze Von Bildung und Wissenschaft. Erwägen Wissen Ethik 20 (2009). Heft 2. S. 239-248.

2 NT.: Kontroversität é aqui traduzido por "controvertibilidade", termo empregado sobretudo no campo jurídico, e não "controversialidade", pouco frequente e decerto ligado ao termo inglês controversial. $\mathrm{O}$ termo que adotamos combina melhor com o contexto pedagógico de abertura à possibilidade de diversas controvérsias nos processos de conhecimento e de ensino.

3 NT.: Perspektivität não deveria aqui nos remeter a "perspectivismo", termo que remonta a Nietzsche e parece hoje mais empregado na antropologia, no contexto do relativismo cultural. "Perspectividade", por seu lado, enquadra-se no jargão de algumas disciplinas da física, como no Teorema de Desargues, e completa-se com "lateralidade", "verticalidade", "projetividade", etc.
} 
áreas; em seguida, ela será exposta a partir de uma visão construtivista do contexto formado por saber e perspectividade; por fim, será feita a defesa de uma renaissance do conceito de formação enquanto minuta de referência para a escola com base nessa compreensão construtivista do saber.

\section{Summary}

In the German academic debate on civic education the necessity of representation of controversies and the prohibition of indoctrination have been accepted as fundamental principles since the Beutelsbach Consensus in the late Seventies. The article examines if and in what sense these principles should be emphasized as principles of education for the education system in general, particularly for schools. The article consists of three parts: Firstly, multiperspectivity will be exposed as a principle for all school subjects. Secondly, the connection between knowledge and perspectivity will be discussed from a constructivist point of view. And thirdly, a renaissance of education (in the meaning of the German term "Bildung") as a general concept for the tasks of scholls based on a constructivist understanding of knowledge will be outlined.

\section{Parte I: Multi-perspectividade Controvertibilidade e proibição de doutrinação: o Consenso de Beutelsbach na formação política}

((1)) No outono de 1976, o novo diretor do centro estadual para a formação ${ }^{4}$ política de Baden-Würtemberg, Siegfried Schiele, convidou para uma jornada em Weinstadt-Beutelsbach, proeminentes cientistas da recémcriada didática da formação política. O tema da jornada era o questionamento

\footnotetext{
4 NT:: O autor explica no parágrafo ((29)) o termo Bildung e sua tradução para o inglês, geralmente como education. Em nossa tradução, sempre que aparecer "formação", trata-se de Bildung, no original. Esse uso já está bem estabelecido no caso de Bildungsroman, traduzido como "romance de formação", termo inventado para um gênero literário criado por Goethe, contemporâneo de Humboldt, que é uma fonte importante no texto de Sander. Já o termo "educação" pode ser a tradução de Bildung (geralmente no caso de termos compostos, mais ligados a aspectos institucionais, como em Bildungsystem, que é "sistema educacional") ou a tradução de Erziehung.
} 
sobre um possível consenso mínimo na formação política (cf. SCHIELE; SCHNEIDER, 1977). Como pano de fundo dessa questão, ocorria uma forte polarização política dentro dos departamentos acadêmicos: a influência da Nova Esquerda no campo do movimento estudantil tinha produzido esboços de formação política, que a compreendiam como elemento da luta política para as mudanças da sociedade; como contramovimento, no lado conservador, foi exigida uma tomada de partido da formação política em favor da ordem política e econômica estabelecida; na política educacional prática, em diversos estados, sobretudo Hessen e Nordrhein-Westfalen, ocorreram conflitos parcialmente severos em torno de novos programas de ensino e livros didáticos para a formação política. Esse confronto perpassou, no início da década de 1970, a práxis, a política educacional e a ciência. Parecia que a autonomia pedagógica e científica de um discurso acadêmico não poderia se afirmar contra a lógica da luta política - não era a primeira vez na história da formação política, que, desde os primórdios da escolarização moderna na Alemanha, tinha se tornado repetidas vezes instrumento de grupos de interesses políticos (cf. SANDER, 2004).

((2)) O resultado substancial da jornada de Beutelsbach foi o assim chamado "Consenso de Beutelsbach". Não se trata de uma resolução e nem de um acordo; esse consenso não foi sequer explicitamente objeto de deliberação na jornada mesma. Schiele abriu caminho para um tal consenso antes de um modo extremamente hábil, ao pedir que Hans-Georg Wehling, um colaborador de seu centro estadual, redigisse um relatório da jornada visando possíveis pontos de consenso, que foi incluído nas atas da jornada. Wehling anotou a respeito nesse relatório o que se segue:

((3)) "Três princípios fundamentais da formação política parecem-me fora de objeção:

1. Não-dominação. Não se pode permitir que os alunos - com quaisquer que sejam os meios - sejam tomados de assalto no sentido das opiniões desejadas e, com isso, impedidos na 'conquista do juízo independente de cada um'... (cf. Friedrich Minssen, W. S.) Exatamente aqui se estende a fronteira entre formação política e doutrinação. A 
doutrinação é, contudo, irreconciliável com o papel do professor em uma sociedade democrática e com a meta - geralmente aceita - da emancipação dos alunos.

2. O que é controverso na ciência e na política deve também no ensino aparecer como tal. Esta exigência está intimamente ligada à anterior, pois quando pontos de vista diferentes ficam escondidos, as opções diminuem, as alternativas permanecem sem discussão, avança-se no caminho para a doutrinação...

3. O aluno deve ser promovido à condição em que possa analisar uma situação politica e sua própria posição de interesse, bem como buscar meios e caminhos para exercer influência sobre a posição em que se encontrava antes no sentido de seus interesses..." (WEHLING, 1977, p. 179).

((4)) Essa impressão confirmou-se rapidamente depois de 1977. Apesar - ou talvez mesmo por causa - do caráter deveras informal do Consenso de Beutelsbach, seus princípios desencadearam um efeito admirável no período que se seguiu. Sem prejuízo de diversos debates em detalhe, de modo especial aqueles sobre a formulação do terceiro princípio e sobre a questão prática de sua aplicação (cf., entre outros, SCHIELE; SCHNEIDER, 1980; SCHIELE; SCHNEIDER, 1987; SCHIELE; SCHNEIDER, 1997), o Consenso de Beutelsbach tem na didática de formação política um valor incontestável - e mais ainda: ele é um elemento central da autocompreensão profissional de uma formação política democrática. Para o recomeço da formação política na Alemanha Oriental depois da reunificação alemã, ele foi um importante texto de referência. E desde os anos 1990, no contexto da crescente internacionalização da discussão acadêmica sobre a didática da formação política, cresceu fortemente também o interesse internacional pelo texto traduzido nesse ínterim para inúmeras línguas.

((5)) De fato, as singelas formulações desse relatório do colóquio, de modo especial nos dois primeiros pontos com a proibição da doutrinação ("não dominação") e com o preceito sobre a controvertibilidade, demarcaram mais que um acordo pragmático de facto para superar uma 
confrontação política em torno de uma especialidade escolar nos anos 1970. Esses dois princípios implicaram, pelo contrário, na forte hipótese da diferença entre a ocupação profissional com a pedagogia e as posições políticas privadas dos educadores e, portanto, entre o papel profissional e o papel de cidadão, e na hipótese da conexão que há entre essa diferença e a democracia. Essas suposições podem ser reconstruídas da seguinte maneira: nas democracias, as cidadãs e os cidadãos devem ser entendidos (também contrafatualmente) como sujeitos que, de modo independente, são pensantes e capazes de julgar; por isso a "maioridade" vale como ideia condutora geralmente aceita para a formação (pública) e o ensino; a doutrinação não se concilia com essa ideia condutora; por conseguinte, a situação pedagógica profissional dos educadores não se mostra na transmissão efetiva das posições políticas próprias ou decretadas, mas sim no fomento da formação de juízos independentes por aqueles que aprendem, mediante a representação de controvérsias durante as aulas. As posições pessoais de conteúdo por parte da professora ou do professor para o objeto concernente de discussão não podem de modo algum ser propostas ou o serão como uma dentre diversas posições da ciência e da política representadas no ensino. Por isso, conforme Wehling esclarece no segundo ponto do Consenso de Beutelsbach, "tornam-se proporcionalmente desinteressantes o ponto de vista pessoal do professor, sua origem teóricocientífica e sua opinião política" (WEHLING, 1977, p. 179), ou seja: secundários para a determinação de sua tarefa profissional.

((6)) Ora, considerando-se à primeira vista, deixa-se compreender a questão que com isso se levanta a respeito da relação adequada à perspectividade nos contextos educacionais enquanto pergunta pelo trato com opiniões e pontos de vista pessoais em relação a uma coisa. A coisa mesma saiu quase intacta disto; consequentemente seria preferível então uma aula em certa medida "neutra", que se referisse essencialmente, então, a essa coisa e só depois complementarmente à multiplicidade de possíveis avaliações e valorações dessa coisa. Contudo, isso é consideravelmente encurtado e são subestimados os desafios levantados pela proibição de doutrinação e pela disposição em favor da controvertibilidade. $\mathrm{Na}$ área temática da formação política, à qual o Consenso de Beutelsbach de fato se 
refere, a "coisa" só se constituirá de maneira realmente aberta e justamente por meio do indício do controverso: "A política toca, segundo Hannah Arendt, no fato da pluralidade das pessoas.” (ARENDT, 1994, p. 9) Ela só surge em geral, porque a partir de diferentes necessidades e interesses resultam diferentes representações e daí perspectivas do regramento e para regular situações que envolvem o coletivo em uma sociedade. Por isso, "na política cada coisa é coisa de alguém.” (SUTOR, 1992, p. 10) Uma atitude reflexiva, que desvela a controvérsia como aspecto central da coisa mesma, deveria ser exigida, enquanto consequência, do Consenso de Beutelsbach para o ensino na formação política.

\section{Multi-perspectividade como princípio didático geral}

((7)) Com o Consenso de Beutelsbach, a formação política comprometeu-se com uma compreensão de seu campo temático, que reage contraintuitivamente a uma expectativa, que está disseminada em grande parte da esfera pública, dos pais e do alunado, e que conforme a pesquisa sobre o ensino, também marca a ação cotidiano do magistério: a escola deve em primeira linha mediar o "saber seguro" e justamente nisso consiste seu "encargo educativo". (Não se deve discutir aqui as problemáticas da demanda muitas vezes concomitantemente reivindicada por "mais instrução" na escola.) Essa equiparação corriqueira de "formação" com uma compreensão marcadamente positivista de saber, tem pouco a ver com a tradição teórica do pensamento educacional; deve-se voltar ainda a isso mais adiante. Isso certamente não vale apenas para a formação política. Em todas as áreas do saber (escolar) tornou-se insustentável a ingênua suposição de que o saber escolar poderia representar a realidade externa da maneira como ela objetivamente é: "Tampouco pode o ensino mostrar o mundo mesmo, mas apenas uma imagem dele. Por isso, pode o ensino no melhor sentido apenas tornar legível o mundo, como um 'texto', que no quadro da transmissão cultural já está previamente interpretado" (DUNCKER, 2005, p. 12) A interpretação, entretanto, implica sempre perspectividade, e a transmissão cultural deixa-se apenas compreender como um complexo, tenso e contraditório conglomerado de visões perspectivistas da realidade. 
((8)) Ludwig Duncker vê por causa disso um modo multiperspectivistico de lidar com a realidade no centro de uma moderna didática geral e da categoria profissional de professoras e professores em todas as especialidades acadêmicas (DUNCKER, 2005). O que foi dito acima sobre política vale, segundo Duncker, com uma variação determinada, para todos os assuntos: "Sob uma consideração multiperspectivistica torna-se possível atingir e reconhecer várias miradas de diferentes lados sobre os objetos, de modo que a imagem que daí venha a surgir seja dependente do ponto de vista que é a cada momento adotado. Com isso, torna-se até nítido que só a perspectiva constitui o objeto da observação (DUNCKER, 2005, p. 10). Com isso, a multiperspectividade (ou, segundo outras formulações, a variedade de perspectivas) torna-se um principio didático central em cada disciplina. Esse princípio continua nesse ponto a ser concebido como o princípio da controvertibilidade, de acordo com o Consenso de Beutelsbach, enquanto relação de diversas perspectivas com um objeto, que não precisa necessariamente ser marcado pelas controvérsias em todas as especialidades. Perspectivas diferentes podem também se completar, se enriquecer, ser entendidas como alternativas umas às outras, provocar surpresas e muito mais; na política, as diferentes perspectivas vão se misturar por aí com interesses diversos e assim pelo menos levar consigo o embrião da controvérsia. Até aqui, a controvertibilidade pode ser entendida como uma forma especial de multiperspectividade que é sem dúvida da maior relevância, especialmente para a formação política.

((9)) No âmbito de um painel interdisciplinar, as cientistas e os cientistas de diferentes didáticas acadêmicas na cidade de Giessen puderam mostrar a fecundidade do princípio da multiperspectividade em temas e materiais de suas especialidades (DUNCKER; SANDER; SURKAMP, 2005). Dentre outros, fazem parte diversos processos de desconstrução e de reconstrução ao se observar uma imagem em uma disciplina de artes (Axel von Criegern), "Quatorze maneiras de descrever a chuva", na música (Thomas Phleps), formas da troca de perspectiva em disciplina de literatura em língua estrangeira (Carola Surkamp) ou a contraposição de diferenciadas relações com a natureza em crianças e jovens na disciplina Biologia (Jürgen Mayer). Até mesmo para a matemática foi possível 
mostrar, por exemplo, na geometria descritiva, que diversas perspectiva são possíveis e são dirigidas "por meio de exigências, necessidades e afirmações", além de que de modo geral, na matemática - disciplina em que há sempre um claro certo ou errado - a ideia é "apenas meia verdade": "a própria inequivocidade de uma solução em muitos casos não ocorre em situações mais complexas. Contudo, assim que entra em questão a relação entre a teoria formal, sua expressão e uma situação real com ajuda da matemática, oferece a matemática apenas uma (ou diversas) perspectiva(s) para essa situação. A utilização de conceitos e procedimentos matemáticos não fornece normalmente nenhuma instrução para a ação em uma situação em que se deve tomar decisão" (STRÄSSER, 2005, p. 68).

((10)) A didática atual pode, no que tange ao princípio da multiperspectividade, remeter inteiramente aos primórdios do moderno pensamento teórico sobre a educação, no início do século XIX. Wilhelm von Humboldt tinha do saber e da formação uma compreensão bastante aberta, sustentada nas ambiguidades da compreensão do mundo. O "entrelaçamento de nosso eu com o mundo", como Humboldt enxergava a formação (HUMBOLDT, 1903, p. 34) não era pensado como algo contínuo e livre de tensão. Pelo contrário, ela deve, segundo Humboldt, "tomar em consideração a diversidade das cabeças, a variedade das maneiras como o mundo se espelha em diferentes indivíduos. Por isso, ao mesmo tempo deveria essa obra estampar também a variedade e, entre aqueles que se destacaram em uma especialidade qualquer, não poderia omitir ninguém que tivesse angariado para a obra uma nova forma ou um conceito ampliado. Essa obra deveria retratá-los em sua completa individualidade e pela grande influência que sua época e sua nação tivessem exercido sobre ela" (HUMBOLDT 1903, p. 37). E de fato Hans-Christoph Koller indica acertadamente que o pensamento educacional de Humboldt é marcado ao mesmo tempo pela ideia de um todo, em que a diversidade dos homens se desenvolve rumo a uma forma complexa de unidade (KOLLER, 1997). Não obstante, o moderno princípio didático da multiperspectividade está muito mais próximo da compreensão de Humboldt sobre a variedade enquanto aspecto central dos processos educativos do que do endurecimento da formação cidadã dentro do cânon da burguesia tardia ou daquele 
entendimento do saber enquanto "estofo" que deve ser "apropriado", "mediado" e comprovado como um condensado do saber seguro, que marca profundamente até hoje a cultura escolar.

\section{Parte II: saber \\ O saber enquanto projeto: perspectivas construtivistas}

((11)) Diante da praxis predominante do ensino, a multiperspectividade altera , portanto, a compreensão do saber, que deve ser adquirido nos processos educativos. $\mathrm{O}$ saber está ligado estruturalmente à perspectividade e, sem ela, não se põe à nossa disposição. Isso não significa que todas as perspectivas imagináveis sejam igualmente significativas - de modo que daí seja indiferente a opção por uma ou por outra - e nem significa que o saber científico tenha o mesmo status que qualquer outra forma de saber. O saber, porém, depende da perspectiva que as pessoas contraponham à realidade externa. Muito antes do moderno construtivismo, Denis Diderot descreveu de maneira extremamente adequada esse contexto no artigo "enciclopédia" em que prestou contas a si mesmo e ao público leitor quanto às metas e aos problemas da secular obra homônima, que ele durante vinte e cinco anos, a partir de 1751, editou juntamente com D’Alembert. Com toda a clareza viu Diderot que também sua tentativa de reunir na enciclopédia o saber sobre o mundo não iria de modo algum copiar a ordem do mundo, mas antes construir uma tal ordem: "Pois não nasce tudo que sabemos do uso de nossos sentidos \& do uso de nossa razão?... Então, não se exclua dessa grande classificação básica o arbítrio. $\mathrm{O}$ universo apenas nos oferece coisas especiais, infinitamente muitas, quase sem qualquer classificação fixa \& determinada; daí que não haja nenhuma coisa que se possa chamar de primeira ou última; tudo se conecta $\&$ se produz por meio de transições imperceptivelmente finas. E se desse imenso mar de objetos alguns se sobressaem como cumes de montanhas \& parecem dominar a superfície, então agradecem esse mérito apenas a sistemas especiais, vagas convenções \& certas casualidades especiais, mas não a organização natural das coisas $\&$ do propósito da natureza... Ora, o universo... tem infinitamente muitos pontos de vista, sob os quais pode ser exposto \& a quantidade dos possíveis sistemas do saber humano é tão 
grande quanto o número desses pontos de vista" (apud SELG; WIELAND, 2001, p. 74) Perspectivas não são outra coisa senão os "pontos de vista" dos quais Diderot fala aqui.

((12)) O construtivismo moderno deu a essa maneira de ver uma sustentação duradoura (o alcance da literatura especializada e o abrangente debate sobre o construtivismo na crítica e na contracrítica não podem ser aqui expostos; consultem a introdução atenta às questões pedagógicas em Lindemann (2006) e Siebert (2005). Mesmo quando as teorias construtivistas são muitas vezes designadas como "pós-modernas" e vistas em uma falsa contraposição como desvio da tradição do Esclarecimento ou como contraposição a ela, o construtivismo está profundamente ancorado na história da filosofia e deixa-se já apoiar sobre posições fundamentais de filósofos iluministas como Diderot ou Kant. Sem dúvida, a linha de tradição cética e de crítica do conhecimento que procede do Esclarecimento foi coberta durante muito tempo por um otimismo diante do progresso, que tinha, nos séculos XIX e XX, fortes resultados culturais e que se nutriu de fontes muito diferentes (desde um positivismo das ciências naturais, passando pela técnica e pela indústria até teorias teológicas da história). Entrementes, deve-se designar como ingênua a ideia - imanente a esse otimismo do progresso - de que um dia, por meio de um saber sempre crescente e objetivamente certo, o mundo que envolve o homem se deixará compreender de modo completamente racional e poderá ser corretamente descrito - ora abstraindo por completo dos fatais efeitos colaterais sociopolíticos do "desencantamento técnico-instrumental do mundo", que deviam ser inspecionados nas catástrofes do sangrento século XX e que Max Horkheimer e Theodor W. Adorno tão acertadamente resumiram em uma frase de sua Dialética do Esclarecimento: "Mas a Terra completamente esclarecida brilha nos signos da desgraça triunfal" (HORKHEIMER; ADORNO, 2003, p. 9).

((13)) Do ponto de vista construtivista, cada saber é um construto e tem como tal caráter de projeto; pode dar bom resultado ou não e, se ele der certo, consegue para os homens uma realidade estável e confiável, na qual eles podem se orientar, viver e sobreviver. Mas o saber não é definitivamente 
"verdadeiro", pelo menos não no sentido de um conceito de verdade dentro da teoria da correspondência, pois nas teorias construtivistas preferese falar de "viabilidade" (utilidade no sentido de oportuno para a vida) e não de "verdade". (Isso sem dúvida não versa por completo contra a "verdade" enquanto ideia regulativa, que é de fato imprescindível para todo discurso racional, e de modo especial na ciência. Cf. parágrafo 15 abaixo). Numa diferenciação conforme ao método dos tipos ideais, três planos se apresentam nessa construção da realidade (cf. detalhadamente em SANDER, 2005, 47ss):

1. O plano da determinação biológica: como outros seres vivos, os homens são equipados com órgãos dos sentidos, que são adequados às possibilidades e limites das respectivas necessidades vitais e que por isso se diferenciam entre espécies. As capacidades humanas de ver, ouvir e o sentido tátil são como que adaptados a nosso "Mesocosmos", conforme denominação da biologia evolutiva - predestinados para um âmbito, que podemos alcançar, com uma sensibilidade para temperatura, que é altamente diferenciada em um campo estreito e que não é capaz de fazer distinções em ambientes frios demais ou quentes demais, com uma sensibilidade intuitiva do tempo, que vai mais ou menos do ritmo das batidas do coração até a duração de uma vida, com uma capacidade visual para cores que lhes permite identificar bem o que é comestível, etc. (cf. SCHEUNPFLUG, 2001, 90ss). Nós vivenciamos o ambiente como espaço tridimensional, sobre o qual certamente Kant já sabia que esse espaço não é um indício da ordem dos objetos, mas sim nossa visão [Anschauung] do mundo. A biologia mostrou muito nitidamente que os órgãos dos sentidos de outros seres vivos podem se distinguir dos nossos, e que estes, com uma verossimilhança que se aproxima da certeza, produzem outras representações do mundo exterior - outras imagens coloridas (ou imagem nenhuma), imagens acústicas espaciais, imagens à base de luz polarizada ou ultravioleta, que nos são invisíveis, percepção com um sentido magnético e outras mais. O grau de incompreensibilidade de nossa construção cotidiana da realidade nesse nível elementar é mostrado não só pelas realidades totalmente modificadas em consequência de acidentes e enfermidades (como se pode, por exemplo, nos inúmeros trabalhos populares de Oliver Sacks, 
com descrições plásticas), mas também pelas realidades de modo algum doentias, mas igualmente nítidas de pessoas com percepções sinestéticas, que, por exemplo, veem sons ou podem ouvir cores. Construções nesse plano são em certa medida automatizadas e igualmente bastante incapazes de sofrer deliberada influência ou de sofrê-las apenas em medida muito limitada; elas aparecem assim como evidentes e até mesmo como objetivamente certas. Não obstante, elas se tornarão reconhecíveis no mais tardar em comparação com as possibilidades perceptivas de outros seres vivos, enquanto uma forma muito elementar de perspectividade humana - que certamente enquanto tal apenas pode ser sabida e reflexivamente relativizada, mas que só dificilmente pode ser mudada na prática ou não o pode ser de modo algum.

2. O plano sociocultural: pertence já às peculiaridades biológicas do ser humano que nossa espécie seja tão pouco determinada quanto ao tipo e nos modos de organização e realização da convivência de tal modo que no decorrer da história da espécie o homem realizou uma variedade simplesmente incalculável de formas de vida. Se a história humana for considerada como história da cultura, evidencia-se ao mesmo tempo que as agremiações sociais desenvolveram e desenvolvem ainda uma variedade de compreensões do mundo altamente diferenciadas - o que conta como "realidade" variou e varia drasticamente entre sociedades, grupos sociais, religiões, comunidades que compartilham uma visão de mundo e grandes espaços culturais. Mesmo pequenos grupos, como, por exemplo, as famílias, podem, por sua vez, produzir ideias específicas de realidade (social), que se distinguem de outras. "A construção social da realidade", conforme o título de um clássico da moderna sociologia (BERGER; LUCKMANN, 2004), é o plano em que se impõem as necessidades e interesses coletivos, bem como as relações de poder e dominação; "a determinação da realidade pode ser enrijecida pela polícia” é o que consta em Berger/Luckmann de maneira tão lapidar e acertada (BERGER; LUCKMANN, 2004, p. 128) Em outras palavras, no plano sociocultural, as perspectivas se entrelaçam frequentemente com interesses. 
3. O plano da interpretação individual do mundo. Apesar dessas "molduras" biológicas e socioculturais, a construção da realidade se distingue mais uma vez entre pessoas em particular. Para uns, diferentes disposições genéticas e para outros, distintas experiências de vida mesmo no interior de um grupo social podem promover diferentes compreensões de mundo entre os indivíduos. A construção da realidade vai se diferenciar entre os homens exatamente porque o mundo se apresenta diferente a cada um em particular no decorrer de sua vida, por causa das diferentes pessoas que cada indivíduo encontra. Por isso, cabe na verdade a suposição de que a margem de manobra para construções da realidade individualmente distintas não é exatamente do mesmo tamanho em todas as épocas e em todas as sociedades, mas depende do grau de diferenciação do mundo social experimentável para indivíduos e também da aceitação normativa de uma variedade de compreensões de mundo que sabidamente não era e nem é do mesmo tamanho em todas as sociedades. Contudo, nenhuma sociedade conseguiu fazer desaparecer esse plano da construção da realidade, por meio de maciça pressão de adaptação - felizmente, e aliás não apenas por causa de uma em tal caso perdida liberdade individual, mas também por conta da perda aí implicada de capacidade de desenvolvimento e de mudança para a sociedade como um todo.

((14)) Uma tal diferenciação analítica dos diversos planos na construção da realidade pode contribuir talvez para reagir diante de alguns exageros e preconceitos na discussão sobre o construtivismo. A construção da realidade não é, portanto, possível a indivíduos de modo completamente arbitrário, (porque os dois primeiros planos de certa forma determinam a moldura daquilo que é possível) e nem é totalmente determinada (pois, apesar desses dois planos, o pensamento e o comportamento de indivíduos concretos não são previsíveis, afinal de contas). É também pouco significativa a diferenciação, comumente encontrada na literatura, entre um construtivismo "radical" e um outro "moderado" - e, por conseguinte, "social" - porque depende do plano para o qual se olha na construção da realidade e não tanto de quão "radical" se apresente a compreensão construtivista do saber e do conhecer. 
((15)) Aos preconceitos e exageros diante do construtivismo pertence também a suposição (que certamente é transmitida por uma ou outra equivocada declaração oriunda do discurso construtivista) de que a compreensão construtivista do saber não admite qualquer distinção entre qualidades do saber, expectativas de validade fundamentáveis ou não fundamentáveis e nem mesmo entre ciência e superstição. Passa-se antes uma completa "arbitrariedade" no trato com o saber, como é o caso de uma rotulação muito em voga nesse contexto, que prega o "anything goes", mesmo que a frase rápida de Paul Feyerabend (cuja "teoria anarquista do conhecimento" era certamente muito mais complexa do parece sugerir essa resumida citação (FEYERABEND, 1980) escancare as portas para charlatães. De fato, por meio de um tipo de realização, o saber científico se distingue, contudo, de outras formas de saber (como, por exemplo, as convicções religiosas ou o saber intuitivo): o saber científico é obtido metodicamente de acordo com regras transparentes. Sua expectativa de validade é definida em cima das regras metódicas para sua ocorrência; por isso há também evidentemente asserções "certas" e "erradas" em um discurso científico limitado por tais regras. Isso começa pela obrigação de tornar públicas as fontes e as pertinentes regras de citação e vai até arranjos extremamente complexos de experimentos e regras para a interpretação dos dados daí provenientes. Essas regras são, é claro, distintas e muitas vezes controversas dentro de cada ciência e entre campos da ciência, o que acarreta teorias e paradigmas científicos concorrentes entre si. Não obstante, a "verdade" é um conceito indispensável para as ciências - se não tanto em uma compreensão ontológica, mas como ideia regulativa para a comunicação científica, que obriga à fundamentação racional e à transparência do procedimento metódico, no que o aludido proceder metódico não começa só com a pesquisa empírica, mas já com a divulgação de bases e fontes e pelo rigor da argumentação. Sem tais ideias regulativas, a comunicação científica não seria possível, afinal de contas. De fato, é também certo que o saber científico não tenha que ser obrigatoriamente e em todos os casos mais viável que outras formas de saber na superação de problemas no campo da ação. Em relação a isso, Kwame Anthony Appiah conta a bela anedota da irmã missionária na África, que viu que muitas crianças em um lugar remoto adoeciam de diarréia e disso morriam, por 
beberem água de uma fonte, sem antes fervê-la. A irmã explicou aos adultos que eles deviam ferver a água, porque ela continha pequenos seres vivos invisíveis, que adoeciam as crianças. Isso não teve, porém, nenhum efeito. E ela só teve sucesso quando recorreu a uma concepção cultural confiável, ao explicar como escapavam pelas pequenas bolhas na água fervente os espíritos que traziam males às crianças (APPIAH, 2007, p. 60).

((16)) A interdisciplinaridade científica está entre os aspectos especialmente interessantes do construtivismo. Essa interdisciplinaridade não deve, na verdade, ser compreendida de tal modo como se apenas com o construtivismo existisse uma visão "holística" do mundo, que abrangesse todas as ciências ou uma teoria unitária da ciência. Falar do construtivismo no singular já é equivocado, na medida em que poderia mesmo deixarse associar uma tal ideia de unidade. O "construtivismo" deveria, pelo contrário, ser compreendido antes como um nome genérico para uma variedade de abordagens de pesquisa e de teorias, que de fato estão ligadas entre si por meio de suposições básicas da teoria do conhecimento, que, de resto, estão ancoradas em diferentes contextos disciplinares, trabalham com distintas conceitualidades e perseguem concretamente também interesses cognitivos diferentes. Ainda está por vir uma sinopse do construtivismo que cruze todas as disciplinas científicas. Tal visão de conjunto valeria a pena, embora não simplesmente com propósitos de realização, mas até porque as conceitualidades - na qual o pensamento construtivista se expressa nas ciências - são diferentes entre disciplinas diferentes, mas também porque o conceito do construtivismo não é empregado para sua fundamentação em inúmeras obras essenciais e muitas vezes era ainda completamente desconhecido.

((17)) Por isso, aqui só se pode aludir a alguns exemplos como ilustração para a amplitude disciplinar do pensamento construtivista. O construtivismo tem suas raízes primeiramente na filosofia - na modernidade, com destaque para Kant (com precursores na antiguidade) e, mais tarde, na psicologia, com Piaget. Nas ciências sociais, o construtivismo está conceitualmente presente não antes de Berger e Luckmann (2004, primeira edição 1969), mas é também extremamente influente na teoria dos sistemas e 
na fundamentação teórico-científica da pesquisa social qualitativa. De leitura muito clara e com exemplos pitorescos para novas abordagens construtivistas oriundas de outras ciências são, para a linguística, Lakoff/ Johnson (2007); para a biologia evolutiva, Maturama/Varela (1987); para a neurobiologia, Roth (2003); para a ciência da comunicação, os inúmeros trabalhos de Watzlawick (por exemplo, 1976) e, para a ciência histórica, Fried (2004).

((18)) Mesmo na física, perdeu cada vez mais terreno no decorrer do século passado, a marcante suposição - que atingia diretamente essa ciência no início da modernidade - de um mundo que se pode reconhecer, independentemente do observador, de modo objetivamente correto e ontologicamente verdadeiro. Einstein e Infeld, em um livro popular, que foi publicado pela primeira vez já em 1938, utilizaram então uma adequada imagem para o status do saber da física: "Conceitos da física são livres criações do espírito e não produzem algo como aquilo em que tão facilmente se inclina a acreditar necessariamente a partir das relações no mundo exterior. Em nosso esforço, para agarrar a realidade, fazemos muitas vezes como um homem que tentou se intrometer no mecanismo de um relógio de bolso. Ele vê a placa com os números, vê como os ponteiros se movimentam e até escuta o tic-tac, mas não tem nenhuma possibilidade de abrir a caixa. Se ele é astuto o bastante, imagina talvez algum mecanismo ao qual pode atribuir tudo o que vê, embora nunca esteja bem seguro de que sua ideia seja a única que permita explicar suas observações. Ele nunca está em condições de provar suas ideias com base no mecanismo real" (EINSTEIN; INFELD, 1995, 52s.) A física quântica, diante da qual Einstein ainda se punha cético, ainda radicalizou essa visão, na medida em que vê o mundo - diga-se, o mecanismo do relógio de bolso - "como representante de nossos enunciados", de acordo com o físico quântico Anton Zeilinger (ZEILINGER, 2003, p. 225) De acordo com isso, é "evidentemente absurdo perguntar pela natureza da coisa, desde que uma tal natureza, mesmo se devesse existir, sempre está além de qualquer experiência. Poder-se-ia opinar que por meio de perguntas feitas ao mundo,seja possível aproximar-se mais de sua natureza, contudo isso é sempre ligado ao problema de que o salto daquilo que pode ser dito para 
aquilo que concebemos como realidade sempre contém algo de arbitrário e sempre exigem supor propriedades, dimensões, sistemas, objetos, etc., que não estão disponíveis diretamente a partir da experiência." (ZEILINGER, 2003, p. 227) Na verdade, também Zeilinger afirma que há fortes indícios da existência de um mundo independente da observação - tais como a neutralidade [não-influenciabilidade] de eventos físicos individuais e a reprodutibilidade de experimentos -, mas "o que são afinal essas propriedades da realidade? Existem afinal propriedades da realidade? O que podemos sempre saber sobre essa realidade? O que significam essas questões, em que já vimos que a informação tem um papel fundamental? Faria quanto a isso uma sugestão radical: 'realidade e informação são a mesma coisa' ... Daí que nunca seria possível avançar até o cerne das coisas por meio de nossas perguntas. Pelo contrário, levantam-se em vez disso bem fundadas dúvidas sobre se afinal existe de fato uma tal essência das coisas, que fosse independente de informação. O fato de que a essência nunca pode em princípio ser comprovada torna desnecessária, no fim das contas, a suposição de sua existência” (ZEILINGER, 2003, p. 229).

((19)) Tendo em vista a amplitude disciplinar desse pensamento construtivista nas ciências, "o" construtivismo é em si multiperspectivista e torna-se atraente exatamente por meio dessa variedade de diferentes acessos científicos ao mundo. Ao mesmo tempo, as suposições epistemológicas fundamentais do construtivismo apresentam uma nova moldura de referência para o discurso não apenas entre disciplinas científicas individuais, mas também entre culturas científicas como um todo, como a que distingue ciências do espírito (ou da cultura, ou humanas) e ciências da natureza. De fato, do ponto de vista construtivista, diferenciam-se entre si os conceitos, métodos e teorias, por exemplo, da biologia e das ciências do espírito ou da física e da filosofia. Todavia, ao mesmo tempo, a compreensão construtivista de saber e realidade pode colocar em relação de reciprocidade ciências heterogêneas de tal modo que seus acessos ao mundo, de acordo com princípios, não tem mais que ser entendidos como antagônicos, mas podem ser antes vistos como complementares. Até aqui no discurso construtivista se delineia de fato o esboço de uma moderna compreensão do mundo, que interliga as ciências umas às outras - o 
que, exatamente por causa disso, pode apresentar um decisivo ponto de referência para uma nova concepção do conceito de formação.

\section{PARTE III: Formação \\ Uma renaissance necessária: formação enquanto concepção de referência para a escola}

((20)) Na compreensão construtivista de mundo está, por conseguinte, a chance de uma nova ligação entre formação e ciência. A formação não seria então o emprego corriqueiro deteriorado que esse conceito sugere, uma apropriação ora mais ora menos aditiva de saber seguro a partir de um conjunto de ciências representadas na escola e dessa maneira canonizadas. Ela não seria tampouco uma nova edição da participação subjetiva na autocompreensão coletiva de uma camada ou de um milieu social, como era o caso da burguesia alemã do século XIX. Contudo, o conceito formação representaria, sempre e renovadamente aquilo que Humboldt chamou o "entrelaçamento de nosso eu com o mundo" (cf. acima seção 10). Para uma abrangente compreensão científica de "mundo", ao mesmo tempo aberta a diferentes perspectivas, o construtivismo apresenta hoje um quadro de referência que é não apenas o possível, mas o único que, conforme esboçado acima, é comunicável por sobre o amplo campo das disciplinas científicas.

((21)) Uma tal renaissance do conceito formação é então, em todo caso, inegociável para o futuro do sistema escolar, quando sua existência deve ser defendida como tarefa pública também sob as condições de possibilidade de um mercado global da educação. Humboldt já estabelecia sua concepção de formação geral contra a alternativa de um sistema de escolas profissionais e Standesschulen. ${ }^{5}$ Todavia, assim como àquela época teria sido difícil, sem uma conceituação de seu sentido institucional, fundar um sistema público de educação, vale muito mais ainda hoje e no futuro

\footnotetext{
5 NT: Um tipo de ginásio elitista privado, que segregava alunos por estamentos sociais e, eventualmente, por confissão religiosa.
} 
diante da atratividade das alternativas privadas que se erguem a partir das fraquezas das escolas públicas que subsistem. O sistema educacional público, como o conhecemos hoje, só foi implementado no último terço do século XIX; não é absolutamente óbvio que se permaneça existindo ainda pelos próximos 130 anos. É bem possível e até mesmo verossímil que um sistema educacional organizado de ponta a ponta conforme ao mercado e amplamente privatizado, devido à facilitada disponibilidade de fontes de conhecimento, seria hoje funcional e eficiente, do ponto de vista econômico. Aliás, é igualmente verossímil que o preço para uma tal solução poderia ser disparidades sociais e culturais, bem como a entrada sorrateira no sistema educacional de ofertas motivadas por visões de mundo do tipo fundamentalista religioso, por exemplo, que poderiam por em perigo a liberdade e a democracia.

((22)) Considerando a previsível internacionalização do sistema escolar, ganha um peso adicional a pergunta que daí se segue: o que fundamenta as tarefas da escola em um plano conceitual fundamental e o que as interliga de uma perspectiva internacional? Na verdade, da maneira como foi cunhado pelo neo-humanismo alemão em torno de Humboldt, o conceito formação não foi de modo algum nacional-culturalmente intencionado. Factualmente, porém, no decorrer do século XIX, prevaleceram não só na Alemanha, que estabelecia seu estado-nação, entendimentos nacionais-culturais sobre as tarefas para as escolas: a escola devia educar os jovens da nação alemã e não, jovens gregos ou romanos, segundo Guilherme II, por exemplo, em 1890 (SANDER, 2004, p. 42). O estado-nação e a industrialização formavam o contexto em que se desenvolveu prática e politicamente a escola pública obrigatória; europeização, globalização e economia pós-industrial são o contexto em que ela deve determinar suas tarefas futuras, se é que ela deva continuar a existir. Na práxis escolar, já começou há muito tempo a erosão de uma escola ancorada na nação e na cultura: por meio da migração, da internacionalização da cultura da juventude e do mercado de trabalho, do intercâmbio estudantil, de estágios no estrangeiro, do ensino bilíngue, mas também por meio de atores internacionais da política educacional, como 
a Organização para Cooperação e Desenvolvimento Econômico (OCDE) ${ }^{6}$, que, por exemplo, com os estudos do $\mathrm{PISA}^{7}$, geram efeitos consideráveis em sistemas educacionais das nações. Todavia, as escolas estão ainda muito longe de uma "apropriação" teórico-educacional desses avanços.

\section{O não-saber como condição para a formação}

((23)) Considerando-se o aumento da oferta de saberes, que trazem consigo os aludidos desenvolvimentos no sistema escolar e o avanço nas ciências, pode parecer paradoxal quando aqui quase se chega a falar do "não-saber" como uma condição para a formação. De fato, há todavia um contexto estrutural entre a assim chamada "explosão do saber" (ou da "sociedade do conhecimento", como reza um dos muitos rótulos para enquadrar sociedades que se despedem da era da indústria) e a necessidade de poder lidar com o não-saber. Roland Reichenbach lembrou em sua introdução à filosofia da educação que o não-saber já em Sócrates é a condição de cada processo educativo, mas que com isso o "não-saber" não significa o mesmo que "ignorar": "a ignorância reconhecida é não-saber 'ativo', ao passo que a mera ignorância não apresenta nenhum conhecimento". O escândalo em Sócrates consiste, segundo Reichenbach, "em que a 'formação' e o respectivo 'aperfeiçoamento' dos homens começa com uma destruição: as meras opiniões devem ser destruídas, ou seja, enquanto ignorância que são devem ser transferidas e transformadas em não-saber. E com razão Reichenbach acrescenta: "A ideia segundo a qual os processos educativos devem ser entendidos como a transformação da ignorância em não-saber parece apresentar ainda hoje uma provocação" (REICHENBACH, 2007, p. 196).

((24)) A compreensão construtivista do saber chama, pois, a atenção para o fato de que era ilusória a ideia de compreender o não-saber como mero estágio intermediário para o saber definitivamente seguro. $\mathrm{Na}$ verdade,

\footnotetext{
${ }^{6}$ NT.: Organização para Cooperação e Desenvolvimento Econômico, com base em Paris, desde 1948.

7 NT.: Programa Internacional para Avaliação de Alunos, da OCDE. Cf. site do Inep.
} 
as ciências oferecem mais que não-saber até o ponto em que elas, no enquadramento dos seus respectivos cenários teóricos e metodológicos, colocam à disposição o crescente e renovado saber temporariamente seguro. Todavia, com isso, as ciências multiplicam ao mesmo tempo a quantidade de perspectivas sob as quais o mundo pode ser observado. Com isso, cada novo conhecimento dá à luz novas questões abertas - a proliferação do saber científico está inseparavelmente ligada à multiplicação do não-saber. Contudo, cresce ainda mais o risco da fuga para as "meras opiniões", que, para permanecermos ao lado de Reichenbach, garantem a segurança aparente. A educação, que começa com a abertura para o não saber, ganha importância nessa situação também como prevenção política contra a sedução das respostas simples: "Quem entrou em contato prolongado com o universo do não-saber aprendeu também a escrutinar sem reservas suas próprias questões de fundo e, se necessário, a descartá-las. Tal pessoa poderá justamente por essa postura desempenhar um importante papel antifundamentalista na convivência política e não-política" (REICHENBACH, 2007, 22 s.).

\section{Formação como superação de contingência}

((25)) Um "entrelaçamento de nosso eu com o mundo" por meio da educação, que quer fazer justiça a nosso saber atual por meio do saber sobre mundo, só pode ter êxito se transitar por experiências da contingência. Não se deve omitir que esse "pode" contém pressuposições normativas: primeiramente, a pressuposição de que a compreensão científica do mundo deve formar um quadro central de referências para o saber mediado pela escola, e daí, em segundo lugar, o pressuposto de que não são aceitáveis as formas exclusivamente afirmativas de uma conexão de indivíduos com o mundo por meio da educação, que almejam assumir sem reflexão alguém em um grupo, uma camada ou uma classe social ou visam a um milieu cultural (no sentido mais amplo) de uma compreensão predominante de mundo. A formação tem por meta uma forma reflexiva dessa conexão e extrapola, portanto, a mera socialização. Esta é uma implicação cultural e ao mesmo tempo política da educação pelo menos desde a metáfora platônica da caverna, que na verdade se sobrepôs muitas vezes na práxis educativa 
desde a antiguidade por meio de concepções puramente afirmativas de educação e, não obstante, sempre e ainda hoje se manteve atual em reflexões teórico-científicas sobre a educação, apesar dos diferentes enquadramentos teóricos na história da pedagogia - e não se perdeu nada em atualidade nem mesmo na assim chamada pedagogia pós-moderna (REICHENBACH, 2007, 218 s.) e muito menos no construtivismo.

((26)) A formação requer a transição pelo caminho das experiências na contingência, porque o "mundo" com o qual o indivíduo se entrelaça é contingente enquanto cultura humana. Alternativas ofertadas de educação põem os homens a confrontar padrões culturais que auxiliaram outras pessoas a instituir o sentido no mundo contingente - por exemplo, com línguas, arte, matemática, com narrativas históricas e teorias da ciência natural, com modelagem teórica da vida social ou com convicções da fé religiosa - para incitar as pessoas que hoje vivem e crescem a enriquecerem sua própria experiência de mundo em meio à contraposição com esses padrões e tradições culturais. Quanto a isso, trata-se menos de uma questão sobre o conteúdo concreto de um assunto educacional que do trato com ele; não a partir da acumulação do saber, mas sim do jogo igualmente refletido e soberano com a educação que brota do saber. A educação possibilita ao indivíduo conferir sentido e importância a sempre novas situações e com isso empregar de maneira crítica e reflexiva a riqueza e a diversidade da cultura humana de que dispomos hoje. Com isso, a educação amplia as possibilidades de experiência das pessoas - o que não significa que isso seja em todos os casos um processo cômodo e agradável, pois essa ampliação pode também trazer consigo irritação, e o contato sempre disponibilizado com o "universo do não-saber" desencadeará também incertezas.

((27)) Justamente nessa capacidade de jogar produtivamente com o sentido e os significados está também o recurso decisivo que a educação arranja para que pessoas jovens dominem seu próprio futuro. O sociólogo americano Andrew Abbott, em uma saudação aos calouros da Universidade de Chicago, formulou isso como se segue: "Eu tenho defendido que educação é uma qualidade do si-mesmo de alguém no presente. Mas é claro que nós vamos sempre viver 'no presente', mesmo que do ponto em que nos 
encontramos agora, os presentes do futuro se pareçam com coisas fixas. 'Eu vou ser um doutor' ou 'Eu vou escrever um grande romance', dizemos, - como se esses presentes futuros fossem simples e fixos estados do ser. Quando você atinge o futuro - quando você se torna doutor ou escreve o romance - você vai descobrir que seus futuros agoras são exatamente tão contingentes, tão inquietantes e tão 'parecidos com o presente' quanto o presente de vocês hoje. Portanto, ocorre que o cultivo da educação o sentido de uma pessoa mesma que constante e incansavelmente busca novos sentidos em situações e fatos e ideias - é um recurso crucial para o futuro, pois o futuro é uma série de momentos contingentes exatamente iguais ao presente" (ABBOTT, 2007, p. 20). É digno de nota que Abbott, dentro da tradição que vem de Humboldt, enfatize com toda firmeza a educação não atrelada a fins específicos [zweckfrei]: “A razão para serem educados aqui - ou em qualquer outro lugar - é que é melhor ser educado do que não ser educado. A educação é melhor em si e por si mesma. Não porque ela consiga algo para você. Não porque ela seja um meio para algum outro fim. É melhor por ser melhor. Notem que o que eu afirmo nos leva a concluir que a expressão 'objetivos da educação' não faz sentido; a educação não é algo sobre o que seja possível estipular metas. Não tem outro fim senão ela mesma... Educação não tem a ver com conteúdo. E nem mesmo com habilidades. É um hábito ou instância mental. Não é algo que você tem. É algo que você é" (REICHENBACH, 2007, p. 14-16).

((28)) Ora, permite-se certamente acrescentar que o contexto social desse discurso de boas-vindas, o de uma universidade americana de elite, também revela, contudo, que a educação a ser oferecida nessa instituição pelo menos não é prejudicial ao desenvolvimento profissional. Abbott está ciente disso também e ele passa longe de considerar a educação em oposição ao sucesso profissional. A educação, de fato, não há de ser instrumentalmente compreendida, mas, na medida em que ela coloca o indivíduo em uma relação reflexiva com o mundo, fomenta também ao mesmo tempo disposições como a curiosidade, a abertura e a autonomia no pensamento e na ação. Omite-se hoje com excessiva facilidade que também a concepção de formação de Humboldt foi uma pedra angular nas reformas prussianas, que deviam efetuar a modernização da Prússia; a 
libertação do indivíduo em processos de formação sem propósito prefixado e a libertação da sociedade burguesa para fora das restrições da velha ordem feudal eram as duas faces da mesma moeda - a educação não tem finalidade, permanece útil.

((29)) O brilhante texto de Abbott refuta ao mesmo tempo a afirmação preconceituosa que na Alemanha sempre se tem que ouvir no meio do discurso sobre educação: o conceito formação [Bildung] é uma especificidade alemã, uma tradição semântica levemente excêntrica e historicamente ultrapassada, que não é capaz de se conectar internacionalmente - e em especial no âmbito anglo-saxão - ao discurso das ciências da educação. $\mathrm{Na}$ verdade, ocorre que a diferenciação conceitual alemã entre "Bildung" e "Erziehung" não tem equivalente na língua inglesa, e o conceito Bildung não tem, portanto, nenhum conceito imediatamente correspondente em inglês. Mas não é correto dizer que o conteúdo semântico de "education" corresponda ao conceito alemão "Erziehung". "Education" designa muito mais que "Erziehung", o que bem se mostra em um conceito como "adult education" [educação de adultos], que obviamente será traduzido por "Erwachsenenbildung" e não, "Erwachsenenerziehung", o que seria na Alemanha um deslize completo. "Bildung" pode ser entendido do começo ao fim como uma compreensão determinada, e, por conseguinte, como uma qualidade determinada de "education". Daí ser tão aligeirada quanto falsa a contraposição entre uma "Bildungstradition" alemã e uma "literacy" - tradition [tradição de "alfabetização"] anglo-americana, como no caso da tradução de "to be educated" ["ser educado"] para "(gut) erzogen sein" ["ser (bem) instruído" ou "ser (bem) educado"] - www.leo.org por exemplo traduz "educated" ["educado"], laconicamente, como "gebildet" ["educado" ou "formado"].

\section{Controvertibilidade e não-doutrinação como condições para o saber educacional}

((30)) Uma tal compreensão da educação pressupõe que não podem ser arbitrariamente delimitados o montante e as opções de perspectivas sob as quais o saber é produzido nas ciências e oferecido nas instituições educacionais para processos educativos. A liberdade da ciência, que 
inclui a esfera pública e a crítica como "princípios de produção" do saber científico e da controvertibilidade, daí decorrente como indício do discurso científico, é, portanto, uma necessária concretização política dessa pressuposição. A proibição da doutrinação, enquanto consequência para a ação pedagógica, emerge da demanda por espelhar mais adequadamente essa controvertibilidade na oferta de educação e com isso os processos educacionais poderiam ser viabilizados no sentido acima descrito.

((31)) Ora, a problemática que aqui se coloca jaz na palavra "arbitrariamente". Com ela, pretende-se dizer menos a coerção prática da ação para a delimitação de ofertas de aprendizagem por causa de recursos temporais e materiais; isso pode ser completamente superado quando os temas da aprendizagem são escolhidos de tal maneira que pelo menos as controvérsias essenciais a eles ligadas também poderiam ser trabalhadas no tempo disponível, o que é uma questão da profissão didática. Mais difícil é a pergunta se pode haver também em princípio limites substancialmente fundados para a multiperspectividade nas ofertas de educação ou se não devem de modo algum existir. Como é que será o trato com posições extremistas e fundamentalistas e com obscuras doutrinas salvíficas dentro da própria sociedade? Oferecer-se-ia aqui o critério da relação com a ciência para as alternativas de educação em oferta ainda como uma referência possível para uma tal demarcação (embora em muitos casos também ao se considerar mais de perto não esteja certo, pois as fronteiras da ciência são de fora a fora fluidas e frequentemente controversas no interior das ciências mesmas), portanto o problema se coloca de outro maneira no mais tardar ao se considerar a pluralidade cultural em escala global. Pois a concepção de educação, que aqui é representada, é sem dúvida marcada por uma tradição cultural europeia e ocidental e concorre com outras tradições culturais. Exagerando-se um pouco na formulação, colocam-se antagonicamente aqui os princípios do universalismo, que também marcam a compreensão da educação aqui esboçada, e do relativismo cultural. Isso não é de modo algum um conflito abstrato, que só interessa teoricamente, mas antes um dilema de ação de instituições educacionais, que em conflitos interculturais "não podem deixar de" assumir uma conduta. 
((32)) Para lidar com o problema da diferença cultural em uma perspectiva global, Appiah cunhou a elegante fórmula: a "Cidadania do mundo" seria "universalidade mais diferença" (APPIAH, 2007, p. 182). Provavelmente é uma cautelosa orientação - que leva em consideração situações concretas e de modo especial as impressões culturais de destinatários concretos a uma tal fórmula que é teoricamente insatisfatória, mas nas escolas é praticamente o único caminho que se pode trilhar. Certamente permanece o problema do trato com as posições culturais que rejeitam firmemente toda forma de universalidade, como, por exemplo, por causa de uma profunda convicção sobre a supremacia da própria visão de mundo, ao recorrerem ao direito que permite perseguir e até mesmo matar pessoas com outras convicções ou com outros traços culturais. Depois de tudo que se disse aqui sobre educação, deve-se entendê-la como um antídoto contra tais posições. Exatamente aqui se encontra a fronteira da multiperspectividade: na exigência de representar apenas aquelas posições culturais legítimas dentre as ofertas de educação, que por seu lado estão prontas a reconhecer como legítimas outras que não as suas.

\section{Referências}

ABBOTT, Andrew (2007). "Welcome to the University of Chicago". Supplement zu Forschung \& Lehre, 8/2007.

APPIAH, Kwame Anthony (2007). Der Kosmopolit. Philosophie des Weltbürgertums. Munique.

ARENDT, Hannah (1994). Was ist Politik? Munique, Zurique.

BERGER, Peter L.; LUCKMANN, Thomas. (2004). A construção social da realidade. 20. ed. Frankfurt sobre o Meno.

DUNCKER, Ludwig; SANDER, Wolfgang; SURKAMP, Carola (Org.). (2005) Perspektivenvielfalt im Unterricht. Stuttgart.

EINSTEIN, Albert; NFELD, Leopold.(1995). Die Evolution der Physik. 20. ed. Reinbek.

FEYERABEND, Paul. (1980). Erkenntnis für freie Mensch. edição revista. Frankfurt. sobre o Meno.

FRIED, Johannes. (2004). Der Schleier der Erinnerung Grundzüge einer historischen Memorik. Munique. 
HORKHEIMER, Max; ADORNO, Theodor. W. (2003) Dialektik der Aufklärung. Edição especial limitada da reedição de 1969, Frankfurt sobre o Meno.

HUMBOLDT, Wilhelm von (1903) "Theorie der Bildung des Menschen. Bruchstück", in HUMBOLDT, Wilhelm von. Werke 1, 1785-1795, editado por A. Leitzmann, Berlin; aqui citado segundo Heinz.-Elmar TENORTH (Org). Allgemeine Bildung. Analysen zu ihrer Wirklichkeit, Versuche über ihre Zukunft. Weinheim/Munique, 1986.

KOLLER, Hans-Christoph (1977). Bildung in einer Vielfalt von Sprachen. Zur Aktualität Humboldts für die bildungstheoretische Diskussion unter den Bedingungen der Postmoderne, in KOCH, Lutz; MAROTZKI, Winfried; SCHÄFFER, Alfred (Org.). Die Zukunft des Bildungsdenkens. Weinheim.

LAKOFF, George; JOHNSON, Mark (2007). Leben in Metaphern. Konstruktion und Gebrauch von Sprachbildern. 5 ed. Heidelberg.

LINDEMANN (2006). Konstruktivismus und Pädagogik. Grundlagen, Modelle, Wege zur Praxis. Munique.

MATURAMA, Humberto; VARELA, Francisco (1987). Der Baum der Erkenntnis. Die biologischen Grundlagen menschlichen Erkennens. Berna/Munique.

REICHENBACH, Roland (2007). Philosophie der Bildung und Erziehung. Eine Einf "hrung. Stuttgart.

ROTH, Gerhard (2003). Aus Sicht des Gehinr. Frankfurt sobre o Meno.

SANDER, Wolfgang (2004) Politik in der Schule. Kleine Geschichte der politischen Bildung in Deutschland. Marburgo.

SANDER, Wolfgang (2005) Die Welt im Kopf. Konstruktivistische Perspektiven zur Theorie des Lernens. Kursiv - Journal für politische Bildung, 1, 2005.

SCHEUNPFLUG, Annette (2001) Biologische Grundlagen des Lernens. Berlim.

SCHIELE, Siegfried; SCHNEIDER, Herbert (Org.). (1997) REicht der Beutelsbacher Konsens? Stuttgart. 
SELG, Annette; WIELAND, Rainer (Org.). (2001) Die Welt der Encyclopédie. Frankfurt sobre o Meno.

SIEBERT, Horst (2005) Pädagogischer Konstruktivismus. Lernzentriert Pädagogik in Schule und Erwachsenenbildung. 3. ed. Neuwied/Kriftel.

STRÄSSER, Rudolf (2005) Mathematik - ein Wechsel der Perspektive? In: DUNCKER; SANDERSURKAMP 2005.

SUTOR, Bernhard (1992) Politische Bildung als Praxis. Grundzüges eines didaktisches Konzepts. Schwalbach/Ts.

WATZLAWICK, Paul (org.). (2002) Die erfundene Wirklichkeit. 18. ed., Munique.

WEHLING, Hans-Georg (1977) Konsens à la Beutelsbach? Nachlese zu einem Expertengespräch. in: SCHIELE; SCHNEIDER 1977.

ZEILINGER, Anton (2003). Einsteins Schleier. Die neue Welt der Quantenphysik. Munique.

Data de registro: 04/04/2010 Data de aceite: 02/10/2010 